\title{
Natural mortality amoung four common ungulate species on Letaba Ranch, Limpopo Province, South Africa
}

\author{
H.P. CronJe, B.K. ReILly and I.D. MacFadyen
}

Cronje, H.P., B.K. Reilly and I.D. Macfadyen. 2002. Natural mortality amoung four common ungulate species on Letaba Ranch, Limpopo Province, South Africa. Koedoe 45(1): 79-86. Pretoria. ISSN 0075-6458.

Five years of mortality data of impala Aepyceros melampus, blue wildebeest Connochaetes taurinus, buffalo Syncerus caffer and kudu Tragelaphus strepsiceros have been used to describe the minimum mortality profiles of the respective species in an open savanna system with the full compliment of predators. Predation is the principle cause of natural mortalities on the study site, Letaba Ranch, which is adjacent to the Kruger National Park. The principle cause of impala mortality are leopards Panthera pardus and wild dogs Lycaon pictus. Lion Panthera leo were major contributors to the mortality of wildebeest and buffalo. Anthrax Bacillus anthracis was the main cause of kudu mortality.

Key words: predation, predators, impala, blue wildebeest, buffalo, kudu, Letaba Ranch.

H.P. Cronje $\square$ and B.K. Reilly, Department of Nature Conservation, Technikon Pretoria,Private Bag X680, Pretoria. 0001; I.D. Macfadyen, 214 Leonie Street, Doringkloof, Pretoria 0001.

\section{Introduction}

Predation constitutes an important feature of the biotic environments of wild ungulates (Hirst 1969) and the effect of this on small private nature reserves can lead to financial implications. The increased perception of the benefits of tourism especially if the major predators are accommodated, has led to several private undertakings applying for permits to accommodate lion in particular. The availability of mortality data, expressed as a financial benefit or loss relative to tourism benefits, is an important factor in determining the sustainability of undertakings. Several predator-prey studies have been done to describe the impact of predators on wild ungulate species (Mitchell et al. 1965; Hirst 1969; Pienaar 1969; Mills \& Skenk 1992), but they were one-off studies for short periods of time. The effective management of any wildlife undertaking is dependent on the constant availability of information. Mortality registers updated on a weekly and annual basis is a valuable source of information particularly during periods in which game cen- suses are absent. This data is a means to monitor annual mortalities thus effecting the adjustments of ungulate trends over time.

The mortality profiles of impala, blue wildebeest, buffalo and kudu are described. Data was collected and collated from field ranger observations for the period January 1990 to December 1994.

\section{Study area}

The Letaba Ranch Nature Reserve is situated at $23^{\circ} 39^{\prime} \mathrm{S}$ and $31^{\circ} 03^{\prime} \mathrm{E}$ and $100 \mathrm{~km}$ east of Tzaneen in the Limpopo Province, South Africa. The Kruger National Park borders the eastern boundary of Letaba Ranch. The 35000 ha reserve is now totally enclosed by an electrified fence which was not the case at the time of the study.

The topography of the reserve is predominantly gentle undulating landscapes at altitudes between $340-400 \mathrm{~m}$ a.s.l. with the 
occasional hill reaching $450 \mathrm{~m}$ above sea level.

Letaba Ranch is located in a summer rainfall region characterised by hot summers and temperate winters, with the highest and lowest daily mean maximum and minimum temperatures of $31.7{ }^{\circ} \mathrm{C}$ in the summer and $10.1{ }^{\circ} \mathrm{C}$ in the winter. The mean annual rainfall is $487 \mathrm{~mm}$.

Gertenbach (1987), in his study of the vegetation of the Kruger National Park, distinguishes two landscapes also common to Letaba Ranch, namely Colophospermum mopane veld on sandy soils extending over the southern two-thirds of the reserve and the Letaba River rugged veld in the northern third of the reserve.

The larger herbivore component common on Letaba Ranch are impala, blue wildebeest, buffalo, bushbuck, elephant Loxodonta africana, zebra Equus burchelli, giraffe Giraffa camelopardalis, kudu, sable Hippotragus niger, waterbuck Kobus ellipsiprymnus, warthog Phacochoerus africanus and white rhinoceros Ceratotherium simum.

Lion, leopard Panthera pardus, spotted hyaena Crocuta crocuta and black-backed jackal Canis mesomelas are the most numerous ungulate predators. Cheetah Acinionyx jubatus, wild dog and side-striped jackal Canis adustus are present, but not common.

In terms of resource utilisation, Letaba Ranch functioned as a trophy hunting reserve until 1994 (Macfadyen pers. comm.). The rugged and rough terrain, poor roads and scrub mopane all contributed to this utilisation option which had financial benefits higher than that of other eco-tourism ventures (Macfadyen pers. comm.).

\section{Methods}

To collect a large data set on the game mortalities occurring on Letaba Ranch, the rangers who patrolled the reserve on a daily basis were tasked with noting mortality data. Hirst (1969), Pienaar (1969) and Mills (1984) also used this data collection technique. To standardise the classification of age classes by the rangers, examples of the various ages of the ungulates under investigation were demonstrated to the rangers. The age classes of kill data recorded were adult male (ADM), adult female (ADF), sub-adult male (SAM), sub-adult female (SAF), and juvenile (J). The cause of death was determined by the evidence of characteristic predator kill signs (that is the method by which the animals were killed and eaten), dominant tracks at the site of the kill or the visual confirmation of the predator at a carcass. In the event that the cause of death could not be determined, cause of death was recorded as unknown. The miscellaneous (M) category encompassed infrequently recorded mortalities due to crocodile and caracal. Natural mortalities refer to mortalities that were caused by predators or due to intraspecific interactions of a particular species. Although malnutrition is the direct cause of mortality during drought periods, the category drought was chosen to represent malnutrition.

The main source of bias in the technique used to collect mortality data is fortuitous observations (Mitchell et al. 1965; Hirst 1969; Pienaar 1969; Mills 1984) in that for the small prey species and younger age classes, the detection of the carcass was negligible due to the rapid rate at which the carcass was devoured. Thus the data is biased to the larger ungulate and age classes. Data collection is also biased towards the dry season due to the increased visibility and detection of carcasses during this period. With cognisance of these limitations, it is believed that the data presented provides an estimate of the mortalities that can be expected on a reserve accommodating the full spectrum of predators.

The agents of mortality, relative to each ungulate species, were collectively summed with the impact of each agent of mortality expressed as a proportion of the total cause of mortality.

\section{Results and discussion}

Of the four ungulate species, predation on impala was mostly by leopard and wild dog. Lion were responsible for the greater part of deaths among blue wildebeest, buffalo and kudu (Table 1). Over the spectrum of natural mortalities recorded, in descending order of contribution, lion had the greatest impact (27.5\%) followed by leopard (21.3\%), Anthrax (20.5\%) and wild dog with $11.8 \%$ (Table 2). 

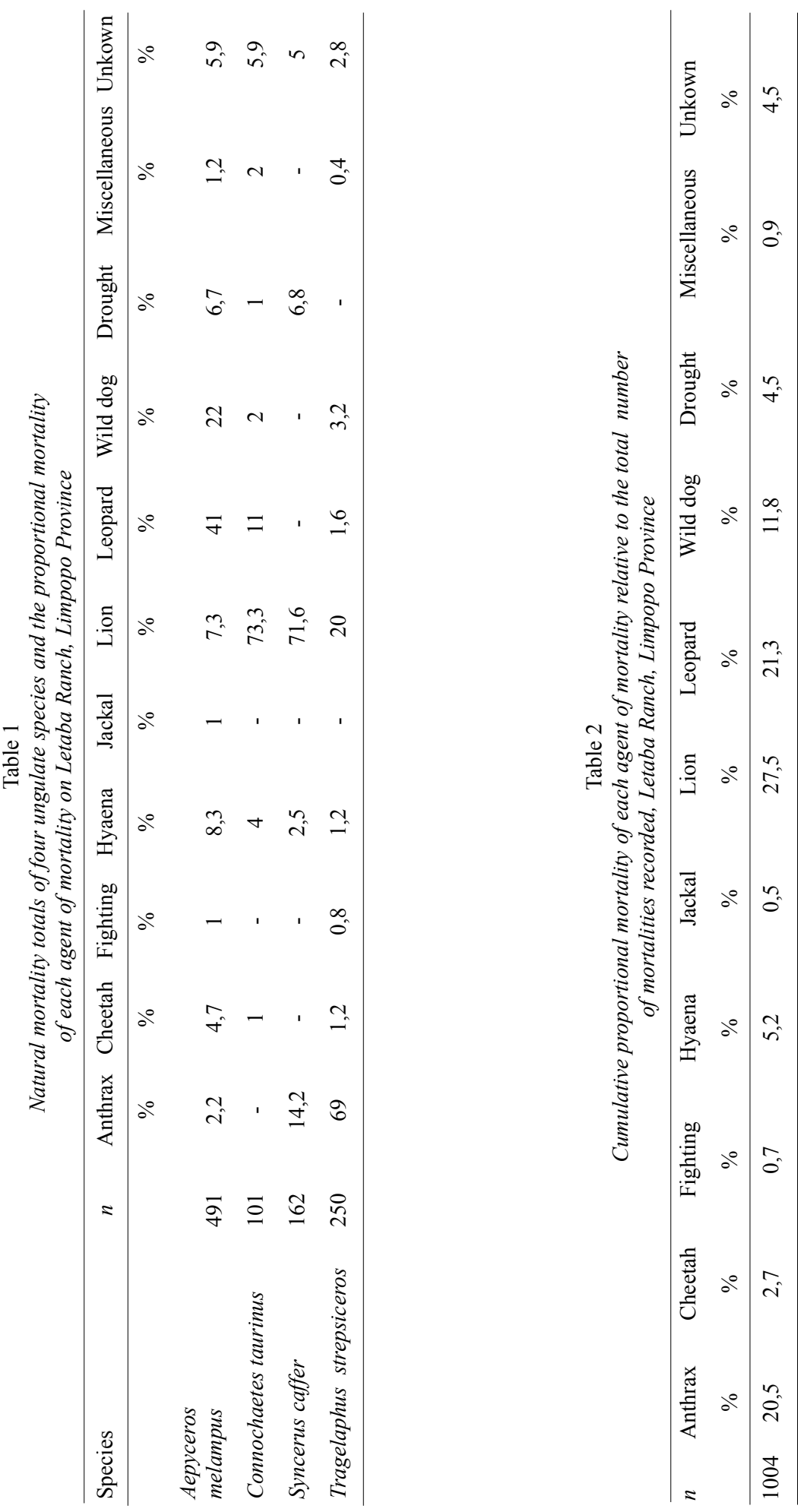


\section{Impala}

Impala were vulnerable to all six predators (Table 1). Although all predators prey on impala to a greater or lesser extent (Skinner \& Smithers 1990), in this study leopard had the greatest impact (41\%). Hirst (1969), Pienaar (1969) and Le Roux \& Skinner (1989) found that leopard are the main predators of impala in the Timbavati (20.7 \%), Kruger National Park (34.3\%) and Londolozi Game Reserve (51\%), respectively. Wild dog had the second highest impact $(22 \%)$ in contrast to the $9.5 \%$ reported by Pienaar (1969) for the Kruger National Park. This may be attributed to the fact that Letaba Ranch is smaller in size and fully fenced, causing predation in the herbivore component to be higher. Hyaena $(8.3 \%)$ and lion (7.3\%) had a smaller impact on impala. Cheetah $(4.7 \%)$ had the lowest impact of all the predators. Cheetah were also reported to be of less importance in the Kruger National Park, where they contributed a $5.8 \%$ mortality of all carcasses recorded (Pienaar 1969). However, in areas where cheetah are in high density and where inter-specific competition is minimal, mortality of impala by cheetah would be expected to be higher. Cheetah are regularly subjected to inter-specific competition (Pienaar 1969; Skinner \& Smithers 1990). Miscellaneous mortalities amounted to $1.2 \%$, occasioned by five crocodile kills and one caracal kill. Anthrax was a minor factor, resulting in mean of $2.2 \%$ over the study period, with
$9.32 \%$ deaths in 1990 , the year of the outbreak.

The percentage mortality of impala per predator within each age class is shown in Table 3. Adult female impala had the highest mortality relative to other sex and age classes by lion $(47.2 \%)$, leopard $(39.7 \%)$ and wild $\operatorname{dog}(49.1 \%)$. For hyaena, adult male and adult female age classes had the same mortality rates. Cheetah seemed to concentrate on the male component with a higher mortality rate $(43.5 \%)$ within the sub-adult male age class. Cheetah generally prey on stragglers on the fringes of the main impala herds (Skinner \& Smithers 1990) which are often of the male gender. Jackals caused the highest mortality $(80 \%)$ of juvenile impala. Newborn lambs of the smaller antelope species are prone to the attention of jackals during the lambing season (Pienaar 1969).

\section{Blue Wildebeest}

Blue wildebeest were preyed on by five different predators. The main predators were lion $(73.3 \%)$ followed by leopard $(11 \%)$ and hyaena $(4 \%)$ as indicated in Table 1. Pienaar (1969), Hirst (1969) and Mills \& Skenk (1992) also found that lion were the major cause of wildebeest mortality. The data in Table 4 shows a high kill ratio for the adult component, with a slightly higher percentage of females $(45.9 \%)$ in relation to the male mortality of $40.5 \%$, resulting from lion. Leopard prey mostly on young wildebeest (Bourliére 1963), which is supported

Table 3

Proportional predation mortality of impala Aepyceros melampus relative to age and sex class, Letaba Ranch, Limpopo Province

\begin{tabular}{lccccccc}
\hline Age-Sex Class & $\mathrm{N}$ & Cheetah(\%) & Hyaena(\%) & Jackal(\%) & Lion(\%) & Leopard(\%) & Wilddog(\%) \\
\hline Adult Male & 143 & 26,1 & 41,5 & - & 30,6 & 38,2 & 30,6 \\
Adult Female & 171 & 21,7 & 41.5 & - & 47,2 & 39,7 & 49,1 \\
Sub-adult Male & 58 & 43,5 & 9,8 & 20,0 & 13,9 & 12,1 & 13,0 \\
Sub-adult Female & 33 & 8,7 & 7,3 & - & 8,3 & 9,0 & 6,5 \\
Juvenile & 7 & - & - & 80 & - & 1,0 & 0,9 \\
\hline
\end{tabular}


Table 4

Proportional predation mortality of blue wildebeest Connocheatus taurinus relative to each age and sex class, Letaba Ranch, Limpopo Province

\begin{tabular}{lccccccc}
\hline Age-Sex Class & $\mathrm{N}$ & Cheetah(\%) & Hyaena(\%) & Jackal(\%) & Lion(\%) & Leopard(\%) & Wild dog(\%) \\
\hline Adult Male & 32 & - & 50,0 & - & 40,5 & - & - \\
Adult Female & 36 & - & 50,0 & - & 45,9 & - & - \\
Sub-adult Male & 4 & - & 0 & - & 1,4 & 27,3 & - \\
Sub-adult Female & 8 & - & - & - & 9,5 & 9,1 & - \\
Juvenile & 12 & 100 & - & - & 2,7 & 63,6 & 100 \\
\hline
\end{tabular}

by the results of this study (Table 4). Juveniles had the highest mortality rate $(63.6 \%)$, followed by the sub-adult males $(27.3 \%)$ and with the lowest, the sub-adult females (9.5\%). Kills by wild dog, hyaena and cheetah were low at $2 \%, 4 \%$ and $1 \%$ respectively.

\section{Buffalo}

As with blue wildebeest, lion predation is also the principle cause of buffalo mortality (71,6\%), which is borne out by the findings of Pienaar (1969) and Mitchell et al. (1965) in the Kruger and Kafue national parks respectively. According to Bourliere (1963) adult buffalo regularly fall prey to lion. The adult female and sub-adult male buffalo age classes had the highest representation in lion kills viz. $35.4 \%$ and $25.4 \%$, respectively (Table 5). Hyaena had a minimal $(2.5 \%)$ effect on the mortality of buffalo (Table 1). Adult buffalo may be too large a prey to be captured by hyaena, especially if hunted singly (Cooper 1990). Hyaena mostly select medium-sized prey but being opportunistic, would take almost anything they can overpower (Cooper 1990). This is supported by the data in Table 5 where it is noted that hyaena tend to concentrate on the younger buffalo component where the opportunity arises. Over the study period, anthrax was responsible for $14.2 \%$ of all deaths. During 1990 , out of a total of 31 mortalities recorded, anthrax was responsible for $23(74.2 \%)$ of those mortalities. Buffalo are infected with anthrax by grazing on vegetation onto which blowflies have regurgitated after feeding on a carcass contaminated with anthrax as well as being infected with anthrax at waterholes (Bothma 1996). The principle source of anthrax infection in buffalo in the Kruger National Park is waterholes (De Vos pers. comm.) and is also assumed to be the case on the Letaba Ranch Game Reserve. In $5 \%$ of the sample, the cause of death was

Table 5

Proportional predation mortality of buffalo Syncerus caffer relative to each age and sex class, Letaba Ranch, Limpopo Province

\begin{tabular}{lccccccc}
\hline Age-Sex Class & $\mathrm{N}$ & Cheetah(\%) & Hyaena(\%) & Jackal(\%) & Lion(\%) & Leopard(\%) & Wilddog(\%) \\
\hline Adult Male & 16 & - & - & - & 13,8 & - & - \\
Adult Female & 41 & - & - & - & 35,3 & - & - \\
Sub-adult Male & 30 & - & - & - & 25,9 & - & - \\
Sub-adult Female & 14 & - & - & - & 12,1 & - & - \\
Juvenile & 19 & - & 100 & - & 12,9 & - & - \\
\hline
\end{tabular}


Table 6

Proportional predation mortality of kudu Tragelaphus strepsiceros relative to each age and sex class Letaba Ranch, Limpopo Province

\begin{tabular}{lccccccc}
\hline Age-Sex Class & $n$ & Cheetah(\%) & Hyaena(\%) & Jackal(\%) & Lion(\%) & Leopard(\%) & Wild dog(\%) \\
\hline Adult Male & 22 & - & - & - & 40,0 & - & 25,0 \\
Adult Female & 24 & - & 66,7 & - & 40,0 & & 25,0 \\
Sub-adult Male & 6 & - & - & - & 12,0 & - & - \\
Sub-adult Female & 10 & 33,3 & 33,3 & - & 8,0 & 75,0 & 12,5 \\
Juvenile & 6 & 66,7 & - & - & - & 25,0 & 37,5 \\
\hline
\end{tabular}

unknown. Two calving-related deaths (1.2\%) were recorded.

\section{$K u d u$}

Kudu were subject to high $(20 \%)$ lioninduced mortality as corroborated by Hirst (1969), with wild dog second highest (3.2\%) (Table 1). In the northern and central districts of the Kruger National Park, Pienaar (1969) found that, amongst others, kudu was one of the species heavily preyed upon by wild dog. During the study, both male and female adult animals had equal mortalities (Table 6). Leopard, hyaena and cheetah were the lowest contributors to kudu mortality. Leopard and cheetah were responsible for the mortality within younger age groups (sub-adult and juvenile) as was also noted by Pienaar (1969) in the Kruger National Park. Hyaena preyed on both adult and sub-adult females (Table 6). Anthrax caused the greatest mortality (69\%) of kudu during the study period. In 1990, of 204 deaths recorded, 171 $(84 \%)$ were anthrax related. Of all ungu- lates, kudu are particularly susceptible to anthrax (Dekker pers. comm.). Kudu are infected in a similar fashion to buffalo (Pienaar 1961; Braack \& De Vos 1990). One kudu was taken by a crocodile $(0.7 \%)$.

\section{Annual and seasonal mortality variation}

The mean annual natural mortalities for impala, blue wildebeest, buffalo and kudu are given in Table 8. Of particular note, are those of buffalo (31 \pm 37.37$)$ and kudu (50 \pm 75.38). The cause of the wide data dispersion for kudu was due to the anthrax outbreak during 1990. That of the buffalo is attributed to excessively high lion predation during 1992. The factors contributing to this high mortality were the stress of buffalo after a capture operation, which had an adverse affect on the herd structure, as well as the occurrence of a drought during 1992 (Macfadyen pers. comm.). Re-computation of the dispersion of the data in the absence of the outliers (trimmed mean) show the mortalities for buffalo and kudu at the $95 \%$ confidence

Table 7

The seasonal distribution of natural mortalities on Letaba Ranch, Limpopo Province

\begin{tabular}{lccc}
\hline Species & $n$ & $\begin{array}{c}\text { Wet season } \\
\text { Jan - Mar/Oct - Dec (\%) }\end{array}$ & $\begin{array}{c}\text { Dry season } \\
\text { Mar - Sept (\%) }\end{array}$ \\
\hline Aepyceros melampus & 491 & 37,5 & 62,5 \\
Connocheatus taurinus & 101 & 47,5 & 52,5 \\
Syncerus caffer & 162 & 42 & 58 \\
Tragelaphus strepsiceros & 250 & 11,6 & 88,4 \\
\hline
\end{tabular}


Table 8

Annual variation in the natural mortalities of four ungulate species on Letaba Ranch, Limpopo Province

\begin{tabular}{lcc}
\hline Species & $n$ & Mean anuual mortality \\
\hline Aepyceros melampus & 491 & $98,2( \pm 44,12)$ \\
Connocheatus taurinus & 101 & $20,2( \pm 5,2)$ \\
Syncerus caffer & 162 & $31( \pm 37,37)$ \\
Tragelaphus strepsiceros & 250 & $50,2( \pm 75,38)$ \\
\hline
\end{tabular}

limit to be $15( \pm 9.92)$ and $15.8( \pm 8.6)$ respectively.

The majority of all deaths recorded occurred during the dry season for all four ungulates (Table 7).

\section{Conclusion}

The juvenile components of all four species are underrepresented in the data in this study, attributed to the rapid rate at which these animals are disposed by predators (Mitchell et al.1965; Hirst 1969).

Migratory animals have a lower mortality in contrast to sedentary animals in national parks that are large enough to allow for the natural migrations of gregarious ungulates (Mills \& Skenk 1992). From this can be concluded that migratory species in restricted areas will be prone to greater mortality, as is the case of Letaba Ranch. In restricted areas where predators (especially lion), are accommodated and the smaller the area, the greater the number of mortalities that can be expected.

Anthrax has the potential to adversely effect ungulate species to a greater or lesser extent and must be taken into account.

The capture and removal of game is a management action commonly used to regulate ungulate populations and is a prime income generator. On areas accommodating predators, particularly lions, cognizance must be taken of the potential post capture increase in predation which may lead to further losses.
The data in this study represents the minimum number of mortalities for impala, blue wildebeest, buffalo and kudu. It is impossible to record the exact number of mortalities occurring in areas where predators are active due to differing hunting techniques, rates at which prey is consumed, remains left and failure of managers to detect carcasses particularly during the wet season when visibility is impaired.

Mortality data should be used in the development of population models that incorporate game count data to derive more accurate data on population trends. Annual game censuses are becoming more irregular due to financial constraints. A population model based on population trends (from long-term species monitoring) and incorporating annual mortality data (natural and unnatural) providing estimates of populations during intervening periods, should be a research priority. Models of this nature would ensure continuous data regarding ungulate trends. Count data combined with population dynamics data provide better decision support than count driven trends alone. Predator prey models also require accurate data on mortalities, particularly where predators are to be reintroduced to conservation areas in the sub-region.

Very often wildlife managers look to expensive and sophisticated procedures to gather data on game populations. This analysis from daily summaries in a managers diary, from good ground coverage by field rangers, show that "primitive" methods are invaluable in gaining insight into the status of species in protected areas. In the light of 
increasing costs of monitoring, declining budgets and expertise in conservation agencies, such inexpensive opportunistic data gathering must be considered in wildlife management undertakings in southern Africa. The effectiveness of this approach is, however, dependent on the number of field staff employed for this purpose relative to the surface area that will require regular surveillance. Ascertaining the competence of field staff in accurately recording mortality and training them where necessary is of paramount importance for the collection of mortality data.

\section{Acknowledgements}

The first author would like to thank Ionka Du Preez for her contiuous support and assitance throughout the preparation of this manuscript. Gratitiude is also expressed to the referees that provided valuble input and added value to the paper.

\section{References}

Bourliére, F. 1963. Specific feeding habits of African carnivores. African Wildlife 17(1): 21-27.

BraAK, L.E.O. \& V. DE Vos. 1990. Feeding habits and flight range of blow-flies (Chrysomyia spp) in relation to anthrax transmission in the Kruger National Park, South Africa. Onderstepoort Journal of Veterinary Research 57: 141-142.

Choquette, L.P.E. \& E. Broughton. 1981. Anthrax Pp. 289-295. In: Davies, J.W., L.H. Karstad \&
D.O. Trainer (ed). Infectious diseases of wild mammals. Ames, Iowa: Iowa State University Press.

COOPER, M.S. 1990. The hunting behaviour of spotted hyaenas (Crocuta crocuta) in a region containing both sedentary and migratory populations of herbivores. African Journal of Ecology 28: 131-141.

GeRTENBACH, W.P.D. 1987. 'n Ekologiese studie van die suidelikste mopanieveld in die Nationale Krugerwildtuin. D.Sc. verhandeling, Universiteit van Pretoria, Pretoria.

Hirst, S.M. 1969. Populations in a Transvaal Lowveld Nature Reserve. Zoologica Africana 4(2): 199-230.

Le RouX, P.G. \& J.D. SKInNER. 1989. A note on the ecology of the leopard (Panthera pardus Linnaeus) in the Londolozi Game Reserve, South Africa. African Journal of Ecology 27: 167-171.

Mills, M.G.L. 1984. Prey selection and feeding habits of the large carnivores in the southern Kalahari. Koedoe (Suppl.): 281-296.

Mitchell, B.L., J.B. Shenton \& J.C.M. Uys. 1965. Predation on large mammals in the Kafue National Park, Zambia. Zoologica Africana 1: 297-318.

Mills, M.G.L. \& T.M. SkenK. 1992. Predator-prey relationships: the impact of lion predation on wildebeest and zebra populations. Journal of Animal Ecology 61: 693-702.

PIENAAR, U. DE V. 1961. The outbreak of anthrax amongst game animals in the Kruger National Park. Koedoe 4: 4-17.

PIENAAR, U. DE V. 1969. Predator-prey relationships amongst the larger mammals of the Kruger National Park. Koedoe 12: 108-187.

SKInNER, J.D. \& R.H.N. SMitheRs. 1990. The mammals of the southern African subregion. Pretoria: University of Pretoria. 